\title{
A obra de Affonso Ávila e sua fortuna crítica
}

\author{
Melânia Silva de Aguiar*
}

\begin{abstract}
Resumo
Apresentação da obra de Affonso Ávila e sua fortuna crítica, baseada, sobretudo, no livro Fortuna crítica de Affonso Ávila, publicado em 2006 pela Secretaria de Cultura do Estado de Minas Gerais e Arquivo Público Mineiro, constituído de cinco seções: I - Poesia; II - Ensaio e pesquisa; III Depoimentos e entrevistas; IV - Cronologia; V - Bibliografia.

Palavras-chave: Affonso Ávila. Poesia. Fortuna crítica.
\end{abstract}

A ideia de se fazer uma homenagem a Affonso Ávila dentro das atividades do Grupo de Estudos de Poesia da Modernidade da PUC Minas - GEPOM - começou a ser gestada no primeiro semestre de 2012, e sobre isto tive a oportunidade de falar mais de uma vez com o poeta. Com a simpatia e a generosidade de sempre, ele se dispôs a vir conversar conosco sobre suas atividades de pesquisador, de ensaísta e de poeta, exatamente hoje, 25 de outubro, dia fixado para nosso encontro na PUC. De algum modo nós o temos e o teremos durante os trabalhos, na pessoa de seus familiares - Míriam e Cristina -, que gentilmente acataram a ideia de representálo aqui hoje; e o teremos também na leitura de seus textos, revisitados que serão na fala dos especialistas que compõem as mesas, e que prontamente aderiram a esta homenagem; além disso, com certeza, nós o teremos nas intervenções e na lembrança saudosa dos participantes deste Colóquio, seus amigos e admiradores.

Para abrir os trabalhos, julguei que seria pertinente apresentar a "obra de Affonso Ávila e sua fortuna crítica" ao modo de uma introdução geral, destinada, sobretudo, aos não tão familiarizados com a sua poesia. Vou-me basear para isso, no livro Fortuna crítica de Affonso Ávila, publicado em 2006 pela Secretaria de Cultura do Estado de Minas Gerais e Arquivo Público Mineiro, de que fiz a Introdução. Mas faremos menção também a textos críticos posteriores a esse livro da Fortuna crítica, constituído de cinco seções: I - Poesia; II - Ensaio e pesquisa; III - Depoimentos e entrevistas; IV - Cronologia; V - Bibliografia.

* Professora da Pontifícia Univesidade Católica de Minas Gerais - PUC Minas - e Universidade Federal de Minas Gerais (aposentada) - UFMG. 
A iniciativa da Secretaria de Cultura de reunir em um volume a Fortuna crítica de Affonso Ávila, além de significativa homenagem e de demonstração de apreço pelo trabalho por ele realizado, é uma relevante contribuição aos estudos sobre sua obra. O acesso dos estudiosos ao que se escreveu em épocas distintas sobre essa produção intelectual, ou ao modo como essa obra foi recebida pela crítica, fica extraordinariamente facilitado, já que, não poucas vezes, ensaios críticos preciosos se perdem com o esgotamento de edições ou o desgaste de textos que vão se tornando cada vez mais raros e de consulta quase que impossível. A publicação, portanto, da Fortuna crítica de Affonso Ávila, em se tratando de quem é este jornalista, poeta, pesquisador, ensaísta, "agitador cultural", como tem sido às vezes lembrado, é, pois, elogiável, sob todos os aspectos. Mineiro de Belo Horizonte, com raízes paterna e materna na velha Itaverava, cidade desbravada por bandeirantes e povoada por antigos mineradores, Affonso Ávila guardou, em sua obra como um todo, esse vínculo com suas origens mineiras e, simultaneamente, na juventude, participou a fundo de um momento novo e relevante da história intelectual de Minas Gerais e do Brasil.

Iniciando sua trajetória de homem atuante em muitos ramos do saber, aos 22 anos já é colaborador do Diário de Minas, assinando com Fábio Lucas, no Suplemento, a seção Tribuna das Letras. Daí para frente, exerceria uma laboriosa atividade intelectual, dando curso a, entre outras, sua vocação jornalística, como colaborador que foi do Estado de Minas e de O Estado de S. Paulo, além de diretor da Folha de Minas. Juntamente com um grupo de jovens intelectuais, fundou em 1951 a revista Vocação. Fábio Lucas, Rui Mourão, Cyro Siqueira, Laís Corrêa de Araújo, com quem se casa em 1952, são alguns desses jovens escritores, que viriam a ter, nos anos que se seguiram, papel expressivo no panorama cultural de Belo Horizonte.

Na seção I da Fortuna crítica encontram-se reunidos textos críticos sobre a obra poética de Affonso Ávila, que vai do livro inaugural - O açude e Sonetos da descoberta, de 1953, até Cantigas do falso Alfonso el Sabio, publicado em 2006. Dois anos depois, em 2008, Affonso Ávila reuniria toda a sua produção poética no livro Homem ao termo, a ela acrescentando Oráculo de etos/42 Responsos de Pítia (2001) e ainda Mínimo (2005), com um só poema fechando o livro, “Crisálida”, o mesmo que abriria, curiosamente, o livro Poeta poente, de 2010. Naturalmente, outros estudos vieram a partir desse Homem ao termo e Poeta poente, posteriores, portanto, a essa Fortuna crítica, de 2006. Mas Affonso Ávila não parou em Poeta poente sua atividade poética e, recentemente, em 2012, lançaria seu belo e último livro Égloga da maçã, que tive a satisfação de ler e comentar com ele, já agora, no final. 
Entretanto, o livro Fortuna crítica não se restringe, como se viu, à obra poética do autor; numa seção II, textos críticos de Benedito Nunes, Wilson Martins, Sônia Viegas, Francisco Iglésias, Guiomar de Grammont, Carlos Herculano Lopes, Aracy Amaral, José Mindlin, entre outros importantes nomes, focalizam a produção ensaística de Affonso Ávila e ressaltam a importância dos resultados obtidos por ele em suas incansáveis pesquisas, principalmente as voltadas para o século XVIII em Minas Gerais. Benedito Nunes, saudando o lançamento da edição organizada por Affonso, em 1967, dos Resíduos seiscentistas em Minas, que contém a edição crítica e facsimilar do Triunfo eucarístico, de 1734, e do Áureo trono episcopal, de 1749, ressalta a relevância da pesquisa levada a efeito pelo estudioso mineiro. Diz o filósofo e crítico do Pará:

Como ensaísta, no livro recém-publicado (...), o autor se volta para a forma de vida, de onde todos esses sedimentos, símbolos, gestos e resíduos emergiram. Pode-se afirmar, portanto, que o ensaio de Affonso Ávila, tão poético no sentido de ser uma busca das origens, da determinação das matrizes fundadoras da vida social e histórica de Minas Gerais, toma o seu impulso e tem a sua razão de ser nas mesmas fontes que sua poesia vem, desde muito, desencobrindo e interpelando. (AGUIAR, 2006, p. 244)

Já a seção III da Fortuna crítica registra entrevistas concedidas por Affonso Ávila a professores e críticos literários: Fabrício Marques, Cláudio Nunes de Morais, Júlio Castañon Guimarães, Maria Esther Maciel, Régis Bonvicino, Ronald Polito são alguns deles; há aí, além disso, entre outros, um precioso depoimento de Laís Corrêa de Araújo, grande intelectual e também poeta, companheira de Affonso por mais de 50 anos. Não resisto à tentação de ler um trecho desse depoimento de Laís sobre Affonso, em 1999, lembrando os tempos iniciais do namoro. Conta Laís:

\footnotetext{
Alguns 'casinhos' ilustram esses anos de 50, 51, 52. Como a minha irmã, por exemplo, perguntando quem era esse rapaz que passara a frequentar nossa casa, carregado de livros e papéis, e assustando-se: "Poeta? Deve ser pobre que nem São Francisco!" Era, sim. Ou a proposta daquele outro da turma, que argumentava que Affonso era “feio, magrelo e desempregado', enquanto ele era um D. Juan, com carreira certa, para ouvir minha resposta imediata: 'É uma questão de Q.I.'. (AGUIAR, 2006, p. 364-366 - destaques da autora)
} 
E prossegue Laís:

$\mathrm{Na}$ sua tranquila indiferença pelos prêmios e medalhas, Affonso Ávila sintetiza numa frase o seu lugar de existência, seu "topos" de abrigo e pouso onde resguarda a sua identidade: 'moro na rua Cristina, 1.300: É esse homem e esse personagem que admiro e amo, agora, nos seus 71 anos, como outrora, nos seus 24 anos. (AGUIAR, 2006, p. 366)

Na seção IV da Fortuna crítica - Cronologia - encontram-se as principais datas e eventos da vida de Affonso Ávila, constituindo, juntamente com a seção V, a da Bibliografia, última do livro, fonte de informações significativas para estudos sobre o Poeta.

$\mathrm{Na}$ impossibilidade de falar de tudo isto, vamos nos deter um pouco mais na Seção I, a da crítica voltada para a produção de poesia, "uma das mais fascinantes obras poético-literárias de nosso país", como a ela se referiu Moacy Cirne, na Revista de cultura Vozes. (AGUIAR, 2006).

Sobre os livros de poesia de Affonso Ávila muito se tem escrito, e muito há por escrever. Ler os textos críticos que compõem essa Fortuna crítica - e muitos trechos, pinçados por nós nos referidos textos, estão presentes nesses alinhavos de vida e obra que aqui estamos tecendo - é acompanhar no tempo o amadurecimento de um poeta e de um pesquisador; é participar dos impasses em que esbarraram suas escolhas voluntárias e suas "encolhas" forçadas; é entender o real significado de uma contribuição cultural, que é também política, e que se manifesta sob os mais diversos modos: no apreço pelo patrimônio artístico das origens, na busca da compreensão de uma certa identidade ou visão de mundo, na pesquisa de formas e linguagens que expressem os novos tempos, na crítica ácida ao preconceito e à repetição de fórmulas surradas e inúteis.

Poeta desde sempre, Affonso Ávila obtém em 1953 seu primeiro prêmio, o Prêmio Othon Lynch Bezerra de Mello, com a publicação de $\mathbf{O}$ açude e Sonetos da descoberta (Belo Horizonte, Imprensa Oficial). Por esse livro de estreia, expressa Henriqueta Lisboa sua admiração (1954), deixando ver em seu juízo crítico muitos dos traços que persistirão nas obras que se seguiriam a esta:

Em $O$ açude e Sonetos da descoberta, o poeta realiza-se com esclarecida fatura, que nada deixa a desejar, de acordo com a sua original maneira de ser. Sua força emotiva está presente no ritmo, no verbo substancial, na mesma escolha do parcimonioso 
adjetivo. Cada um de seus mosaicos se forma de motivos vários - fragmentos existenciais às vezes contraditórios - cuja coerência reside na constância lírica da composição. (AGUIAR, 2006, p. 56)

Mas é em 1957, com a criação, juntamente com Fábio Lucas, Rui Mourão e Fritz Teixeira de Salles, da revista Tendência, de repercussão nacional, que se torna mais conhecido como poeta, possibilitando o diálogo que viria a se firmar, em 1961, com o grupo do concretismo paulista. É desse ano de 1961 a publicação de Carta do solo, que obtém os Prêmios de Poesia Cidade de Belo Horizonte e Cláudio Manuel da Costa. Augusto de Campos, Décio Pignatari, Haroldo de Campos, entre outros, são nomes com quem troca, nessa época, sua experiência poética, tendo início, já em 1962, sua colaboração na revista Invenção, do grupo concretista. Décio Pignatari, no Congresso de crítica literária realizado em João Pessoa, ressalta a importância do depoimento do próprio autor para a compreensão de seu processo de composição em Carta do solo e para a relação desse processo com o programa de Tendência:

De leitura obrigatória é o depoimento de Affonso Ávila sobre seu livro Carta do solo, que classifica de "poesia referencial". Mais do que um depoimento, é um roteiro de seu processo crítico e autocrítico de composição, bem como uma suma da posição do grupo Tendência. (AGUIAR, 2006, p. 69 - destaques da autora).

Antônio D'Elia refere-se ao livro com entusiasmo, observando nessa poesia a presença da justaposição e da "arte de arrancar dos encontros vocabulares as ressonâncias que dão estesia ao verso":

Eu diria que Affonso Ávila, em seu último livro, alcança uma maneira de trabalhar o verso que é, sem dúvida, tecnicamente, a mais acurada de todas as que têm explorado os nossos poetas, de 1945 para cá. (...) Nesse sentido, o seu poema, feito quase sempre de versos de metro curto, no qual muitos de nossos poetas de hoje chegam apenas a uma imitação descolorida de maneiras arcaicas ou neoclássicas, e não a uma recriação, o seu poema fala mais a uma sensibilidade refletida do que ao sentimento. (AGUIAR, 2006, p. 57)

A Semana Nacional de Poesia de Vanguarda, organizada por Affonso Ávila em 1963 por incumbência do então reitor da Universidade Federal de Minas Gerais - UFMG -, Professor Doutor Orlando de Carvalho, reuniu nomes importantes da vanguarda literária e marcou o público que aí compareceu. Além do grupo de 
São Paulo, participaram desse evento, entre outros, Benedito Nunes, Pedro Xisto, Affonso Romano de Sant'Anna, Roberto Pontual, Paulo Leminski. Sobre essa experiência, o depoimento de Affonso Ávila, em Cartas de aluvião: do pensar e do ser em Minas (2000) é esclarecedor:

O material exposto impactava o público relativamente grande presente, pela contundência formal revolucionária dos poemas, entre os quais figuravam trabalhos de jovens mineiros, àquela altura atraídos e meio fascinados pela linguagem de vanguarda. (...) A Semana [Nacional de Poesia de Vanguarda] deu imediato retorno, quanto à sua repercussão, que incluiria seguidas visitas de curiosos, jovens interessados em arte e poesia, e, de modo singular, caravanas de estudantes que os colégios levavam até à então longínqua sede da UFMG na Pampulha. A imprensa local se comportou como diante de um fato novo, com as opiniões divididas entre o choque cultural e a admiração pelo insólito e inusitado. (AGUIAR, 2006, p. 305)

Com a criação poética, Affonso Ávila teve sempre, pela vida afora, compromisso estreito. Após o livro de estreia e do acima mencionado, Carta do solo, publica, em 1969, Código de Minas \& Poesia anterior, título que, segundo Silviano Santiago, traduz a ironia do poeta: "anticódigo de Minas teria sido mais acurado (...)” (AGUIAR, 2006). Posteriormente, em 1997, liberto da censura dos tempos de repressão política, o livro sairia na íntegra. Essa edição integral é saudada por Ronald Polito (1998), como "um dos acontecimentos mais importantes de 1997 na área da poesia". E acrescenta Polito:

Porque esse Código, para além da difícil e articulada síntese de lirismo e sátira, de fulguração e ironia, é antes de tudo um grito, um lamento contundente contra a administração da memória, a mumificação da cultura, o escamoteamento do cinismo público e a anulação da ousadia, ao percorrer os vestígios de um passado que exige outro re-tratamento. (AGUIAR, 2006, p. 76).

Ainda dos tempos da ditadura é o livro-poema Código nacional de trânsito (1972), que sai em tiragem limitada. Sobre esse livro, de título sugestivo, Fritz Teixeira de Salles, considerando a poesia de Affonso Ávila "um profundo e digno ato de coragem; coragem estética e social, coragem criadora, plena dos desafios da hora", escreve no Jornal de Brasília:

No plano da textura ou da fala poética - código é o manual do já sabido. Usar o código é prender a linguagem no seu reduzidismo (sic) omisso. O código só fala de si mesmo: estabelece a ordem 
dentro do limite das conveniências. Diz, não o que precisa ser dito, mas o que convém. Todavia, todo fato - é no fundo - um fato maior e quase sempre latente na sua essencialidade mais substancial. (AGUIAR, 2006, p. 117-118)

Em 1975, seria lançado Cantaria barroca, cujo título já evoca as origens, quando remete a um tipo de pedra cortada com rigor e utilizada na construção de templos e na pavimentação de ruas em Minas Gerais. Na observação de Ana Hatherly (1983), nesta obra, como nas anteriores,

o Autor assume o passado criativamente no aspecto preciso de que fala Borges - no de precursor do futuro. E singularmente (mas esse é o índice do processo criador) é essa constante viagem para o passado (ultrapassamo-nos constantemente, em cada dia da nossa vida) que se torna uma linguagem do poeta atual: como o Autor escreveu, "sob permanente pressão crítica, provocada pela instabilidade das formas em evolução", acaba por ser uma "épica do instante”. (AGUIAR, 2006, p. 109 - grifos da ensaísta).

O Discurso da difamação do poeta é publicado inicialmente em 1976 na revista Colóquio Letras, da Fundação Calouste Gulbenkian, em Lisboa e, posteriormente, em 1978, em São Paulo, constituindo-se em objeto de análise de Moacy Cirne, que ressalta a reduplicação crescente da ideologia colonizadora trazida pela comunicação de massa e a importância do papel da cultura na conscientização desse fato. Dirá Cirne:

A própria arte, em muitos e muitos títulos, tem servido de pasto para o proveito de artistas a serviço da burguesia. São poucos os artistas, escritores e poetas que, no Brasil, assumem o papel social que interessa àqueles que acreditam em nosso futuro - o papel de produtores culturais. Affonso Ávila é um deles. (AGUIAR, 2006, p. 152).

Já o poema-livro Masturbações é de 1980; a ele se seguiria, no ano seguinte, Barrocolagens, poemas-montagem, em separata da revista Barroco n. 12 (1981). Comentando esses poemas, Rogério Barbosa da Silva observa:

Affonso Ávila usa, em Barrocolagens, elementos técnicos e artifícios de nossa era pós-moderna, como o recurso parodístico e a técnica do pastiche - apropriação crítica e múltipla de textos que constrói réplicas textuais capazes de alargar e burlar a possível exaustão de procedimentos criativos. (...) No poema de Affonso 
Ávila, há todo um cenário armado, segundo um projeto que se sustenta através da vértebra estética e particular da literatura barroca. (AGUIAR, 2006, p. 159).

Delírio dos cinquent'anos (1984), em primorosa edição artística, retomando o título Lira dos cinquent'anos, de Manuel Bandeira, "em clave trocadilhesca", ou ainda glosando o da Lira dos vinte anos, de Álvares de Azevedo, atesta uma mudança de dicção na poesia do autor, como lembra José Paulo Paes:

A modulação paronomásica e serial dos elementos de um verso-base, técnica que se tornara uma espécie de marca da fábrica de sua oficina poética e que epígonos de menos talento tentaram baldamente imitar, cede agora lugar ao paralelismo do epigrama de extremada concisão, a explorar hábil e ferinamente as visualidades da frase feita. (AGUIAR, 2006, p. 176).

O belo e o belho (1988) teve também edição artística, feita dessa vez pela Editora Noa Noa, de Santa Catarina. José Américo Miranda, a propósito dessa edição bemfeita e bem cuidada, surpreende-se com o fato de estar a mesma circulando fora do mercado editorial, já que, segundo ele, Affonso Ávila "é, afinal, o mais importante poeta vivo de Minas Gerais". (AGUIAR, 2006, p. 180)

O visto e o imaginado (1990), livro distinguido em 1991 com o Prêmio Jabuti, da Câmara Brasileira do Livro, e A lógica do erro (2002), merecedor em 2003 do Prêmio da Associação Paulista de Críticos de Arte (APCA), são bons exemplos da sempre boa acolhida pela crítica da produção poética de Affonso Ávila. Nesses livros, novas linhas de atuação se apresentam, como as "condensações auto-irônicas", no dizer de Júlio Castañon Guimarães. E prossegue o crítico:

Em seu livro mais recente, A lógica do erro, são retomados vários dos pontos fortes que se encontram ao longo da obra de Affonso Ávila. No entanto, este é um livro excepcionalmente novo (se é que esta expressão seja apropriada para um livro cujo vigor surge da elaboração de uma violência com raízes profundíssimas). (AGUIAR, 2006, 195).

Cantigas do falso Alfonso el Sábio (2006), por sua vez, lançado pelo Ateliê Editorial, de São Paulo, obteve a láurea JK, como parte das comemorações dos 50 anos da posse de Juscelino Kubitschek na presidência da República.

Muitos dos poemas presentes nas obras acima se encontram em antologias nacionais e estrangeiras, como a de autores latino-americanos, editada em Munique por iniciativa de Curt Meyer-Clason; ou a antologia bilíngüe Puentes/Pontes, organizada por Jorge Monteleone e Heloísa Buarque de Holanda. 
Constitui tarefa imensa falar de toda essa larga produção poética e das formas como essa obra veio a público (música, teatro, vídeo). E se é verdade que na produção intelectual de Affonso Ávila a poesia ocupa um espaço privilegiado, não se pode negar o papel importantíssimo que tem, nas preocupações do escritor, a pesquisa histórica e a produção ensaística.

Estudioso persistente do barroco, tão presente em sua poesia, notadamente do barroco mineiro, Affonso Ávila trouxe com seus ensaios uma contribuição notável ao conhecimento desse período em Minas Gerais, legando a gerações sucessivas uma visão renovada de nossa formação cultural, aí incluído o período neoclássico. Estes estudos, tanto mais notáveis quanto mais portadores de um significado de resgate de obras e manuscritos raros advindos de nossas origens e beirando a extinção, persistiram na produção ensaística de Affonso Ávila, desde 1964, quando inicia suas pesquisas sobre o barroco, sendo fonte obrigatória de consulta a quem deseje explorar a história artístico-cultural de Minas.

O livro acima citado, Resíduos seiscentistas em Minas, publicado em 1967, com lançamento na Reitoria da UFMG, receberia no ano seguinte em Brasília o Prêmio Nacional de Ensaio. Francisco Iglésias, entendendo que o século XVIII constitui um desafio para os estudiosos, estando a exigir pesquisas mais extensas e profundas, considera este ensaio um exemplo raro de estudo pioneiro - "admirável como pesquisa e agudeza crítica, bem como pela originalidade. É dessas obras que abrem caminhos, marco de referência na bibliografia mineiriana." (AGUIAR, 2006, p. 475)

A criação e o lançamento do primeiro número da revista Barroco, em 1969, no Festival de Inverno de Ouro Preto, marcaria o nascimento de uma das mais bem-sucedidas revistas culturais do país, reunindo especialistas do Brasil e do Exterior, com ensaios notáveis e, muitos deles, antológicos, sobre as manifestações artísticas do barroco em Minas Gerais e fora de Minas Gerais, nas mais diversas áreas: pintura, música, imaginária, arquitetura, literatura, etc. A revista Barroco, dirigida por Affonso Ávila até 2005, e atualmente por sua filha, Cristina Ávila, tornou-se indissociável do nome de seu fundador. Falar em "barroco" é falar em Affonso Ávila, tal a dedicação e o empenho do escritor à causa da revista e a seu objeto central de estudo.

Não poderia faltar nesse registro de iniciativas ligadas ao barroco, a publicação, em 1970, de O lúdico e as projeções do mundo barroco, livro de estudos primorosos sobre a formação cultural de Minas Gerais, bem como sobre a forte presença do barroco como visão de mundo e marca de uma mentalidade e de um estilo de vida. Este livro, tão bem-sucedido, viria a ser ampliado e reeditado 
em dois volumes em 1994. Nogueira Moutinho expressa sua admiração por este "riquíssimo ensaio", em que o autor, "o maior especialista brasileiro na temática do Barroco", interpreta "não apenas fenômenos estéticos isolados, mas todo o comportamento vivencial do homem inserido no estágio cultural do barroquismo." (AGUIAR, 2006, p. 478)

A estes livros se sucederiam outros de natureza ensaística. Referência, pois, obrigatória, quando o assunto é barroco, Affonso Ávila poderá ser lembrado por outros muitos aspectos de sua multifacetada atuação no campo da cultura, o que poderá ser comprovado, a seguir, nas apresentações dos estudiosos que se juntaram a nós nesta justa homenagem.

\begin{abstract}
Presentation of the works of Affonso Ávila and his critical fortune based on the book Fortuna crítica de Affonso Ávila, published in 2006 by the Secretaria de Cultura do Estado de Minas Gerais e Arquivo Público Mineiro, containing these five parts: I - Poesia; II - Ensaio e pesquisa; III - Depoimentos e entrevistas; IV - Cronologia; V - Bibliografia.
\end{abstract}

Key words: Affonso Ávila. Poetry. Critical fortune.

\title{
Referências
}

AGUIAR, Melânia Silva de. Fortuna crítica de Affonso Ávila. Belo Horizonte: Secretaria de Estado de Cultura de Minas Gerais e Arquivo Público Mineiro, 2006. 